\title{
Effect of saliva contamination on bond strength with a hydrophilic composite resin
}

\author{
Mauren Bitencourt Deprá1 ${ }^{1}$ Josiane Xavier de Almeidaㄹ, Taís de Morais Alves da Cunha², \\ Luis Filipe Siu Lon², Luciana Borges Retamoso3, Orlando Motohiro Tanaka ${ }^{4}$
}

Objective: To evaluate the influence of saliva contamination on the bond strength of metallic brackets bonded to enamel with hydrophilic resin composite. Methods: Eighty premolars were randomly divided into 4 groups $(n=20)$ according to bonding material and contamination: G1) bonded with Transbond XT with no saliva contamination, G2) bonded with Transbond XT with saliva contamination, G3) bonded with Transbond Plus Color Change with no saliva contamination and G4) bonded with Transbond Plus Color Change with saliva contamination. The results were statistically analyzed (ANOVA/Tukey). Results: The means and standard deviations (MPa) were: G1)10.15 \pm 3.75 ; G2) $6.8 \pm 2.54$; G3) $9.3 \pm 3.36$; G4) $8.3 \pm 2.95$. The adhesive remnant index (ARI) ranged between 0 and 1 in $\mathrm{G} 1$ and G4. In G2 there was a prevalence of score 0 and similar ARI distribution in G3. Conclusion: Saliva contamination reduced bond strength when Transbond XT hydrophobic resin composite was used. However, the hydrophilic resin Transbond Plus Color Change was not affected by the contamination.

Keywords: Saliva. Orthodontic brackets. Bond strength. Adhesives.

Objetivo: avaliar a influência da contaminação por saliva na resistência de união de braquetes metálicos colados ao esmalte com um compósito resinoso hidrofilico. Métodos: oitenta pré-molares foram divididos aleatoriamente em quatro grupos $(\mathrm{n}=20)$, de acordo com o material de colagem e a presença de contaminação - G1) colagem com Transbond XT na ausência de contaminação; G2) colagem com Transbond XT na presença de contaminação; G3) colagem com Transbond Plus Color Change na ausência de contaminação; G4) colagem com Transbond Plus Color Change na presença de contaminação. Os resultados foram tratados estatisticamente (ANOVA/Tukey). Resultados: as médias e desvios-padrão (MPa) foram $\mathrm{G} 1=10,15 \pm 3,75 ; \mathrm{G} 2=6,8 \pm 2,54 ; \mathrm{G} 3=9,3 \pm 3,36 ; \mathrm{G} 4=8,3 \pm 2,95$. $\mathrm{O}$ índice de adesivo remanescente (IAR) variou entre 0 e 1 no G1 e no G4; no G2, houve predomínio do escore 0 e distribuição similar no G3. Conclusão: a contaminação por saliva reduziu a resistência de união no grupo que usou a resina hidrofóbica Transbond XT. Por outro lado, a resina hidrofílica Transbond Plus Color Change não foi influenciada pela contaminação.

Palavras-chave: Saliva. Braquetes ortodônticos. Resistência ao cisalhamento. Adesivos.

${ }^{1}$ Graduate Student, School of Dentistry - PUCPR.

${ }^{2} \mathrm{MSc}$ in Orthodontics, Orthodontic Department, School of Dentistry PUCPR.

${ }^{3} \mathrm{PhD}$ Student, Department of Dental Materials - PUCRS.

${ }^{4}$ Full professor - Orthodontics - PUCPR.
How to cite this article: Deprá MB, Almeida JX, Cunha TMA, Lon LFS, Retamoso LB, Tanaka OM. Effect of saliva contamination on bond strength with a hydrophilic composite resin. Dental Press J Orthod. 2013 Jan-Feb;18(1):63-8.

Submitted: June 23, 2009 - Revised and accepted: April 12, 2010

" The author reports no commercial, proprietary or financial interest in the products or companies described in this article.

Contact address: Orlando Tanaka

Rua Imaculada Conceição, 1115 - CEP: 80.215-901 - Curitiba/PR

E-mail: tanakaom@gmail.com 


\section{INTRODUCTION}

The adhesion to dental enamel started, in 1955, after discovery of acid conditioning by Buonocore. The application of an acid to enamel, demineralizes it selectively, making it appropriate to perform adhesive techniques. ${ }^{10}$ This technique provides micromechanic bond between composite resins and enamel, facilitating the attachment of brackets, direct restorations, indirect restorations and adhesive prosthesis. ${ }^{9}$ After enamel demineralization, the application of an adhesive system that penetrates into the microporosities and attaches the enamel to the composite resin is necessary. Basically, the function of enamel etching is the creation of an adhesive area by increasing enamel porosity and surface energy, resulting in better permeation of the adhesive. Thus, the micromechanic attachments of the resin in the porosities does not allow rupture of the enamel, providing greater longevity of bonding. ${ }^{9,10}$ Some factors are capable of negatively influence the quality of adhesion, such as presence of saliva contamination, blood or remaining phosphoric acid. ${ }^{8,14,15,20}$ The contamination by saliva is one of the most frequent defects in adhesion. ${ }^{26}$ Rajagopal et $\mathrm{al}^{14}$ and Sirirungrojying et $\mathrm{al}^{21}$ reported that the enamel etching previous to the adhesive causes a reduction on the adhesive shear bond strength. On the other hand, the self-etching adhesives are considered hydrophilic and according to Trites et $\mathrm{al}^{22}$ can be used in presence of humidity. However, the influence of saliva on the adhesive resistance of brackets bonded with self-etching adhesives still is controversial. Rajagopal et al ${ }^{14}$ observed reduction on the bond strength when orthodontic brackets were bonded with self-etching adhesives in presence of saliva. These adhesive systems gathered the steps of acid conditioning and primer in one re- cipient making it self-etching, which would keep its properties even in humid environment. However, the use of these systems with conventional resins, hydrophobic, would reduce most of this capacity. In this way, the creation of a composite resin with the same hydrophilic characteristics, as Transbond Plus Color Change, would preserve this property. Thus, this work proposes to evaluate the bond strength of metallic brackets bonded to human enamel previously contaminated with saliva and analyze the area of adhesive defect after debonding.

\section{MATERIAL AND METHODS}

Eighty human premolars, donated by the tooth bank of the Catholic Pontifical University of Paraná (PUCPR), were selected, and had their roots sectioned with diamond burs (KG Sorensen) and discarded. The buccal surface of the teeth was positioned against a glass plate in order to allow most of the flat surface to be parallel to the ground. In this position, the crown was fixed, a PVC ring was positioned and the acrylic resin (Jet/Classic) shed over it (Fig 1A). Posteriorly, prophylaxis was performed, in low rotation, with rubber cups and pumice for 10 seconds. This was followed by rinsing and drying for 10 seconds each at a distance of $50 \mathrm{~mm}$.

The 80 specimens were randomly divided in four groups $(\mathrm{n}=20)$, according to Table 1:

"For G1, enamel etching was performed with $37 \%$ phosphoric acid for 15 seconds, rinsed for 10 seconds and dried for 10 seconds. It was followed by adhesive application (Transbond XT primer), insertion of Transbond XT on the bracket base, positioning on the central portion of the enamel under pressure of $400 \mathrm{KgF}$, measured by a tensiometer (ETM) (Fig 1B) and light cured for 40 seconds.

Table 1 - Division of experimental groups.

\begin{tabular}{ccc}
\hline Group & Contamination & Adhesive system \\
G1 & No & Transbond XT primer and Transbond XT \\
G2 & Saliva & Transbond XT primer and Transbond XT \\
G3 & No & Transbond self etching primer and Transbond Plus Color \\
G4 & Saliva & Transbond self etching primer and Transbond Plus Color \\
\hline
\end{tabular}


» For G2, after enamel etching, rinsing and drying according to described in G1, non-stimulated saliva was applied on the surface. The saliva was collected directly from the researcher and applied on the bonding area with the help of a disposable microbrush.

» For G3, a self-etching primer (SEP, 3M/ Unitek,USA) was used which was kept in contact with the enamel for 10 seconds. After that, the bracket was bonded using Transbond Plus Color Change (3M/Unitek, USA) in the central portion of the crown under pressure of $400 \mathrm{KgF}$ and light cured for 40 seconds.

" For G4, after using a self-etching primer (SEP, 3M/Unitek, USA), non-stimulated saliva was applied on the enamel surface. The saliva was collected directly form the researcher and applied on bonding area with the help of a disposable microbrush. Premolars brackets (3M/Unitek, Monrovia, USA) were used in this study, with an area of $14.28 \mathrm{~mm}^{2}$, measured by a digital caliper (Electron digital caliper 227

- Starret). After bracket bonding, the samples (Fig 1C) were stored in a closed recipient with distilled water at $37^{\circ} \mathrm{C}$ for 24 hours. After this period, the shear test was performed, with force applied in the occlusal gingival direction, in a universal testing machine (EMIC DL500R, São José dos Pinhais, PR, Brazil) at a speed of $0.5 \mathrm{~mm} / \mathrm{min}$. The testing machine was connected to a computer with the Mtest software $^{\circledR}$ that registered the maximum debonding values (Figs $2 \mathrm{~A}$ and $\mathrm{B}$ ). After the shear test, the bonding defect was observed through a stereomicroscope with 40x of magnification and the adhesive remnant index (ARI) was analyzed according to Artun and Bergland: ${ }^{2}$ Zero indicates no adhesive residue on the dental structure; 1 , less than half of adhesive residue on the dental structure; 2 , more than half of adhesive residue on the dental structure and 3 , all the adhesive residue adhered to the bracket.

\section{STATISTICAL ANALYSIS}

\section{Bond strength}

The Kolmogorov-Smirnov and Levene's tests were used to verify the normality and homogeneity of variance, respectively. Normality and homogeneity obtained, the difference between groups was examined through the analysis of variance (ANOVA) and Tukey HSD multiple comparisons tests at a significance level of 5\%.
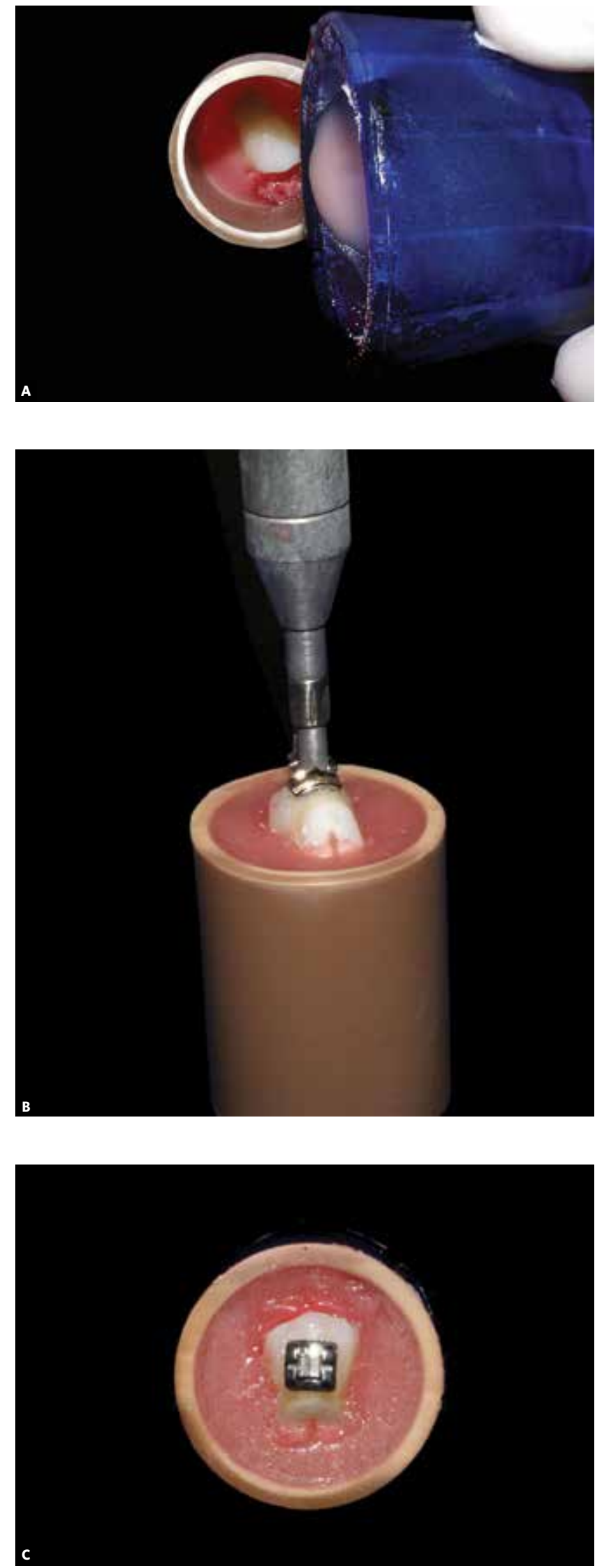

Figure 1 - Sequence of specimen confection. A) Tooth positioning, B) Pressure exerted on the bracket to standardize the thickness of the material, C) specimens finished. 

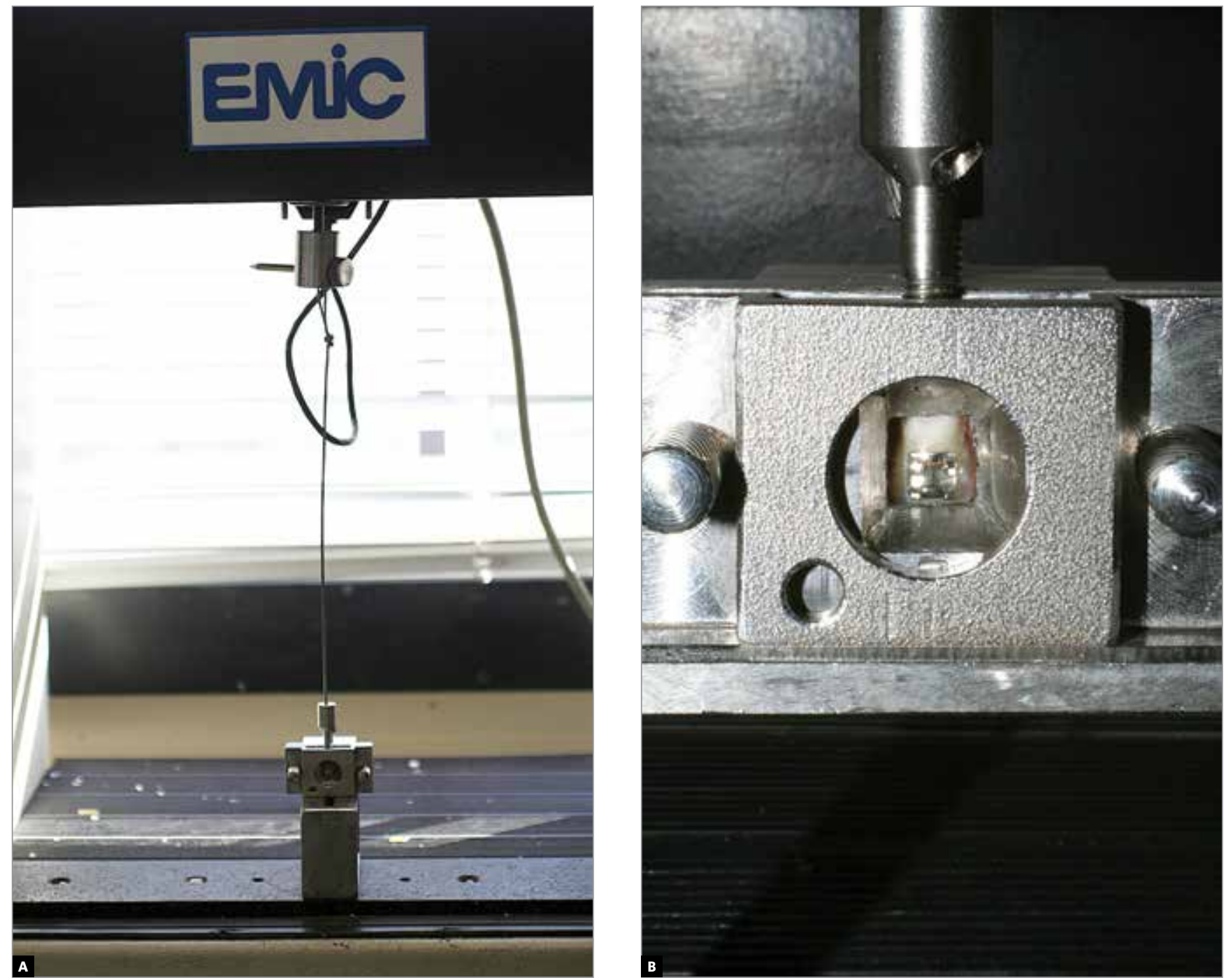

Figure 2 - Mechanical test: A) matrix used on the shear bond strength test, B) detail of the force applied in the occlusal gingival direction.

Table 2 - Descriptive statistic for bond strength

\begin{tabular}{|c|c|c|c|c|c|}
\hline Groups & $\mathbf{n}$ & Contamination & Resin & Mean & Standard-deviation \\
\hline G1 & 20 & No & Transbond XT & $10.15^{A}$ & 3.75 \\
\hline G2 & 20 & Saliva & Transbond Plus & $6.80^{B}$ & 2.54 \\
\hline G3 & 20 & No & Transbond XT & $9.30^{A}$ & 3.39 \\
\hline G4 & 20 & Saliva & Transbond Plus & $8.30^{A}$ & 2.95 \\
\hline
\end{tabular}

NOTE: different letters indicate significant difference by Tukey HSD $(p<0.01)$.

Table 3 - Descriptive statistic for adhesive remnant index (ARI).

\begin{tabular}{|c|c|c|c|c|c|c|c|}
\hline \multirow{2}{*}{ Groups } & \multirow{2}{*}{$\mathbf{n}$} & \multirow{2}{*}{ Contamination } & \multirow{2}{*}{ Resin } & \multicolumn{4}{|c|}{ ARI scores (\%) } \\
\hline & & & & 0 & 1 & 2 & 3 \\
\hline G1 & 20 & No & Transbond XT & 40 & 30 & 10 & 20 \\
\hline G2 & 20 & Saliva & Transbond Plus & 90 & 10 & 0 & 0 \\
\hline G3 & 20 & No & Transbond XT & 25 & 30 & 25 & 20 \\
\hline G4 & 20 & Saliva & Transbond Plus & 40 & 40 & 20 & 0 \\
\hline
\end{tabular}




\section{Bond strength $X$ Bond strength index}

The correlation between bond strength and bond strength indication was obtained through application of the Spearman correlation test.

\section{RESULTS}

\section{Bond strength}

The Tukey HSD multiple comparison test identified significant statistical difference between the G1 and G2 ( $\mathrm{p}<0.01)$, indicating that the contamination by saliva reduces shear bond strength when the hydrophobic resin Transbond XT is used (Table 2).

\section{Adhesive Remnant Index (ARI)}

Most specimens from G1 and G2 presented BSI ranging from 0 to 1 . On $\mathrm{G} 2$ there was predominance of ARI 0. The specimens from G3 presented balanced distribution of ARI (Table 3).

The coefficient of Spearman's linear correlation was of 0.26 , which indicates a weak correlation between shear bond strength and ARI.

\section{DISCUSSION}

The bonding contamination is a problem commonly found on the direct bracket bonding technique, especially in posterior teeth surgically exposed. ${ }^{14}$ Among the main contaminants, stand out saliva and blood contamination. There is divergence about the influence of saliva on the shear bond strength. According to some studies, ${ }^{4,5,18}$ this contamination reduces bond strength. On the other hand, some reports $3,16,21,23$ show no difference on bond strength. These differences might be explained by the adhesive system used. Most of the articles in which the bond strength does not show reduction after the contamination used self-etching adhesive systems. This can be explained by the hydrophilic characteristics of these adhesives. ${ }^{22}$ The results of the in vitro researches can be influenced by the thickness of the resin and direction of the force applied described by Eliades and Brantley. ${ }^{12}$ Aiming to eliminate these factors, a tensiometer was used to standardize the thickness of the composite and the force used during the bonding procedure. Besides, all the experiment was performed by only one operator, as recommended by Ajlouni et $\mathrm{a}^{1}$ and Bishara et al. ${ }^{6}$ The bonding strength of the self-etching adhesives is also controversial. Authors ${ }^{5,25,27}$ reported statistically significant bonding strength reduction when self-etching adhesives were used. However, in this research, the bond strength was similar to the adhesives with previous acid conditioning. It is suggested that the hydrophilic characteristic was kept using a resin with the same property. But yet, there are no reports that evaluated the bonding strength of the hydrophilic resin Transbond Plus Color Change. Thus, studies are recommended to confirm this result. This way, during the choice of the bonding material, some factors must be considered: resistance, longevity, sensibility and ease for removal without dental surface damage. These can be evaluated in vitro and transposed to private practice through the evaluation of the shear bond strength and the adhesive remnant index (ARI) ${ }^{11,17}$ In relation to bracket debonding, Bishara et al. ${ }^{4}$ mentioned that when the adhesive defect occurs on the enamel-adhesive interface there is great risk of enamel fractured. Unlikely, the defect occurring on the adhesive/bracket interface or on the adhesive layer, the dental structure will normally be preserved $^{7,13,25}$. Thus, the adhesives used in this research did not represent risk, for most of the bonding defects occurred on the adhesive layer (score 1 and 2 - ARI), reducing significantly the chances of fracture on the enamel. Only G2 presented high frequency of score 0 . Regarding longevity of the bonding procedure, there are evidences that show that the resistance of adhesives with previous acid conditioning reduces after thermocycling. Saito et $\mathrm{al}^{19}$ theorized that this fact is explained by the hydrophilic property and presence of HEMA in these self-etching solutions. Before these described properties, we recommend that in situations of imminent saliva contamination, the brackets should be bonded with an adhesive system and composite with hydrophilic characteristics, increasing the adhesive resistance and, consequently, the longevity of the bonding procedure.

\section{CONCLUSION}

The saliva reduces shear bond strength when brackets are bonded with hydrophobic resin Transbond XT. However, bond strength is not affected by the contamination by saliva when brackets are bonded with adhesive system and resin with hydrophilic properties (Transbond Plus + Transbond Plus Color Change). 


\section{REFERENCES}

1. Ajlouni R, Bishara SE, Oonsombat C, Denehy GE. Evaluation of modifying the bonding protocol of a new acid-etch primer on the shear bond strength of orthodontic brackets. Angle Orthod. 2004;74(3):410-3.

2. Artun J, Bergland S. Clinical trials with crystal growth conditioning as an alternative to acid-etch enamel pretreatment. Am J Orthod. 1984;85(4):333-40.

3. Bishara SE, Gordan VV, VonWald L, Olson ME. Effect of an acidic primer on shear bond strength of orthodontic brackets. Am J Orthod Dentofacial Orthop. 1998:114(3):243-7.

4. Bishara SE, Gordan VV, VonWald L, Jakobsen JR. Shear bond strength of composite, glass ionomer, and acid primer adhesive systems. Am J Orthod Dentofacial Orthop. 1999:115(1):24-8.

5. Bishara SE, VonWald L, Laffoon JF, Warren JJ. Effect of a self-etch primer/ adhesive on the shear bond strength of orthodontic brackets. Am J Orthod Dentofacial Orthop. 2001;119(6):621-4

6. Bishara SE, Oonsombat C, Ajlouni R, Laffoon JF. Comparison of the shear bond strength of 2 self-etch primer/adhesive systems. Am J Orthod Dentofacial Orthop. 2004;125(3):348-50.

7. Brown CR, Way DC. Enamel loss during orthodontic bonding and subsequent loss during removal of filled and unfilled adhesives. Am J Orthod. 1978:74(6):663-71.

8. Campoy MD, Vicente A, Bravo LA. Effect of saliva contamination on the shear bond strength of orthodontic brackets bonded with a self-etching primer. Angle Orthod. 2005:75(5):865-9.

9. Carvalho RM, Yoshiyama M, Pashley EL, Pashley DH. In vivo study of the dimensional changes of human dentin after demineralization. Arch Oral Biol. 1996:41(4):369-77.

10. Carvalho RM. Adesivos dentinários: fundamentos para aplicação clínica. Rev Dent Rest. 1998:1(2):62-95

11. De Munck J, Van Landuyt K, Peumans M, Poitevin A, Lambrechts P, Braem $M$, Van Meerbeek B. A critical review of the durability of adhesion to tooth tissue: methods and results. J Dent Res. 2005:84(2):118-32.

12. Eliades T, Brantley WA. The inappropriateness of conventional orthodontic bond strength assessment protocols. Eur J Orthod. 2000;22(1):13-23.

13. Joseph VP, Rossouw PE. The shear bond strengths of stainless steel orthodontic brackets bonded to teeth with orthodontic composite resin and various fissure sealants. Am J Orthod Dentofacial Orthop. 1990;98(1):66-71.

14. Rajagopal R, Padmanabhan S, Gnanamani J. A comparison of shear bond strength and debonding characteristics of conventional, moisture-insensitive, and self-etching primers in vitro. Angle Orthod. 2004;74(2):264-8.
15. Reddy L, Marker VA. Ellis E 3rd. Bond strength for orthodontic brackets contaminated by blood: composite versus resin-modified glass ionomer cements. J Oral Maxillofac Surg. 2003:61(2):206-13.

16. Retamoso LB, Collares FM, Samuel SMW, Ferreir ES. Influência do sistema adesivo na resistência de união de "brackets": um estudo in vitro. Rev Facul Odontol Porto Alegre. 2006; 47(3):17-22

17. Retamoso LB, Onofre NML, Marchioro EM. Avaliação de diferentes fontes de polimerização na resistência de união de braquetes. Rev Clín Ortod Dental Press. 2008:7(2):74-8

18. Romano FL, Tavares SW, Nouer DF, Consani S, Borges, AMMB. Shear bond strength of metallic orthodontic brackets bonded to enamel prepared with self-etching primer. Angle Orthod. 2005;75(5):849-53.

19. Saito K, Sirirungrojying S, Meguro D, Hayakawa T, Kasai K. Bonding durability of using self-etching primer with 4-META/ MMA-TBB resin cement to bond orthodontic brackets. Angle Orthod. 2005 Mar;75(2):260-5

20. Schaneveldt S, Foley TF. Bond strength comparison of moisture-insensitive primers. Am J Orthod Dentofacial Orthop. 2002:122(3):267-73.

21. Sirirungrojying $S$, Saito K, Hayakawa T, Kasai K. Efficacy of using self-etching primer with a 4-META/MMA-TBB resin cement in bonding orthodontic brackets to human enamel and effect of saliva contamination on shear bond strength. Angle Orthod. 2004;74(2):251-8

22. Trites B, Foley TF, Banting D. Bond strength comparison of 2 self-etching primers over a 3-month storage period. Am J Orthod Dentofacial Orthop. 2004;126(6):709-16

23. Vicente A, Bravo LA, Romero M, Ortíz AJ, Canteras M. Shear bond strength of orthodontic brackets bonded with self-etching primers. Am J Dent. 2005;18(4):256-60.

24. Webster MJ, Nanda RS, Duncanson MG Jr, Khajotia SS, Sinha PK. The effect of saliva on shear bond strengths of hydrophilic bonding systems. Am J Orthod Dentofacial Orthop. 2001;119(1):54-8

25. Yamada R, Hayakawa T, Kasai K. Effect of using self-etching primer for bonding orthodontic brackets. Angle Orthod. 2002;72(6):558-64.

26. Zachrisson BJ. A posttreatment evaluation of direct bonding in orthodontics. Am J Orthod. 1977:71(2):173-89.

27. Zeppieri IL, Chung $\mathrm{CH}$, Mante FK. Effect of saliva on shear bond strength of an orthodontic adhesive used with moisture-insensitive and self-etching primers. Am J Orthod Dentofacial Orthop. 2003:124(4):414-9. 